\section{Antibodies against AIDS proteins}

SIR-The human immunodeficiency virus HIV-1 encodes several regulatory proteins (in addition to the virion structural proteins gag, pol and env), including vif, vpr, $v p u$, tat, rev and nef $f^{\prime}$. We have investigated the presence of antibodies against some of these regulatory proteins in human sera to determine whether any of them could indicate the progression of HIV infection from the asymptomatic stage to full-blown AIDS.

It is known that putative vif protein, expressed in bacteria, reacts with sera from HIV-1-infected individuals at all clinical stages ${ }^{2}$. By contrast, antibodies against a transregulatory gene product, rev, of HIV-1 predominantly occur in the sera of patients with ARC (AIDS-related complexes) ${ }^{3}$. We have re-examined the reactivity of antibodies against vif and rev in sera of HIV-1-infected individuals at various clinical stages and, in contrast to previous reports ${ }^{3}$, our findings are consistent with the idea that antibodies against vif protein appear early in HIV-1 infection and disappear as clinical signs of AIDS appear, whereas antibodies against rev protein are present at all clinical stages of HIV-1 infection.

The vif gene encodes a protein of relative molecular mass $27,000(27 \mathrm{~K})$ and of unknown function; mutants of HIV-1 deleted in the vif gene produce approximately 1,000 -fold less infectious virus compared with the wild type ${ }^{4}$. The vif protein seems to be necessary for the HIV-1 to recognize CD4-positive lympho-

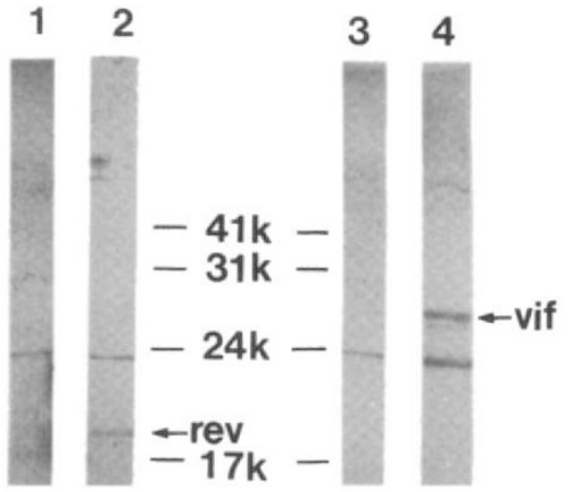

Western blot of vif and rev. Recombinant baculovirus carrying either vif (AcNPV-vif) or rev gene (AcNPV-rev) was used to infect Spodoptera frugiperda (SF9) celis. The infected cells were collected $72 \mathrm{~h}$ post infection, total cellular protein was subjected to SDS-PAGE, transferred to nitrocellulose filter and incubated with HIV-1-infected human sera. The reaction was completed after washing and incubations with horseradish peroxidaseconjugated anti-species antibody and precipitable substrate (4-chloro-1-napthol). Lanes 1 and 3, wild-type baculovirus (AcNPV)-infected SF9 cell extracts; lane 2, AcNPV-rev-infected SF9 cell extracts; lane 4, AcNPV-vif-infected SF9 cell extracts. The band just below the $24 \mathrm{~K}$ marker is a non-specific protein. cytes as the vif deletion mutants could still spread HIV-1 from cell to cell by fusion as efficiently as the wild-type virus. This suggests that vif is a minor structural component of HIV-1. Functional expression of the HIV-1 rev protein is required for synthesis of $g a g$ and $e n v^{5,6}: r e v$ is a $20 \mathrm{~K}$ nuclear regulatory phosphoprotein ${ }^{7}$ which

Prevalence of antibodies against vif and rev in HIV-1-infected individuals

\begin{tabular}{lcc}
\hline Disease stage & $\begin{array}{c}\text { No. of Total } \\
\text { vif } \mathrm{Ab}^{+} / \text {tested } \\
(\%)\end{array}$ & $\begin{array}{c}\text { No. of Total } \\
\text { rev Ab }\end{array}$ \\
$\begin{array}{l}\text { Asymptomatic } \\
\text { (CDC group I) }\end{array}$ & $17 / 52(32.6)$ & $18 / 52(34.6)$ \\
$\begin{array}{l}\text { Asymptomatic } \\
\text { (CDC group II) }\end{array}$ & $8 / 22(36.3)$ & $9 / 22(40.9)$ \\
$\begin{array}{l}\text { ARC patients } \\
\text { (CDC group III) }\end{array}$ & $0 / 18(0)$ & $4 / 18(22.2)$ \\
AIDS patients & $0 / 27(0)$ & $6 / 27(22.2)$ \\
\hline
\end{tabular}

HIV-1 positive sera were determined by western blots and gp41-recombinant ELISA. Ab, antibody.

induces structural gene expression by activating the sequence-specific nuclear export of incompletely spliced messenger RNA species of HIV-1 (ref, 8). This protein increases stability of unspliced viral mRNA but does not affect the stability of multiple spliced viral mRNAs not containing the rev-responsive element ${ }^{9}$.

We have analysed antibodies against vif and rev in several HIV-1-infected individuals using the vif and rev proteins expressed in SF9 cells infected with recombinant baculoviruses carrying either the full length vif or rev gene of HIV-1 under the control of the polyhedrin gene promoter. The level of intracellular vif and rev expression in the infected cells $72 \mathrm{~h}$ after infection was approximately 25 and 15 per cent, respectively of the total cellular protein (see figure). vif and rev could both react with antibodies in certain sera.

We next examined sera from 52 HIV-1infected healthy donors, $22 \mathrm{HIV}$-1-infected healthy donors at risk, $18 \mathrm{ARC}$ patients and 27 AIDS patients (see table). Our results are consistent with the suggestion that antibody against $v$ if is produced early in HIV-1 infection and disappears as the disease progresses to ARC and AIDS. This disappearance could signal the appearance of the clinical signs of HIV-1 infection. In contrast, antibody against rev is present at all stages of HIV-1 infection.

These results differ from those of Chandra et $a l .^{3}$, who found the rev antibody predominantly in the sera of ARC patients ${ }^{3}$. This difference could be due to the source of vif and rev. Chandra et al. ${ }^{3}$ used antigens expressed in bacteria which, in our hands, show a high degree of nonspecific cross-reactivity whereas vif and rev expressed in insect cells show a clean background in western blots. We also note that human antibodies against vif and rev are relatively weak compared with other HIV-1 proteins, indicating that in natural infection these proteins are poor antigens. Furthermore, antibodies produced in rabbits against vif proteins expressed in insect cells demonstrate that $v i f$ is poorly immunogenic.

YAIR DEVASH

KEVIN REAGAN

DAVID WOOD

Medical Products Department,

E. I. DuPont Co.,

Wilmington, Delaware 19898, USA

JOHN TURNER

Department of Medicine,

Graduate Hospital, One Graduate Plaza,

Philadelphia, Pennsylvania 19146, USA

MARK PARRINGTON

C. YONG KANG*

Department of Microbiology and

Immunology,

University of Ottawa

Ottawa, Ontario K1H 8M5, Canada

* To whom correspondence should be addressed

1. Gallo, R. et al. Nature 333, 504 (1988).

2. Kan, N.C. et al. Science 231, 1553-1555 (1986)

3. Chanda, P.K., Ghrayeb, J. \& Wong-Staal, F. AIDS Research and Human Retroviruses 4, 11-16 (1988).

4. Strebel, K. et al. Nature 328, 728-730 (1987)

5. Feinberg, M.B., Jarrett, R.F., Aldovini, A., Gallo, R.C. \& Wong-Staal, F. Cell 46, 807-817 (1986).

6. Sodroski, J. et al. Nature 321, 412-417 (1986).

7. Cochrane, A., Kramer, R., Ruben, S., Levine, J. \& Rosen, C.A. Virology 171, 264-266 (1989)

8. Malim, M.H., Hauber, J., Le, S.-Y., Maizel, J.V. \& Cullen, B.R. Nature 338, 254-257 (1989)

9. Felber, B.K., Hadzopoulou-Cladaras, M., Cladaras, C. Copeland, T. \& Pavlakis, G.N. Proc. natn. Acad. Sci. U.S.A 86, 1495-1499 (1989).

\section{Trans-kingdom promiscuity}

SIR-Two examples of horizontal transfer of DNA from a prokaryote to eukaryote have so far been described. The beststudied case is the transfer of agrobacterial T-DNA from the bacterium to the genome of a susceptible plant cell ${ }^{1}$. This conjugation-like exchange introduces plant oncogenes and facilitates a complex symbiotic relationship between these two organisms. A second, unexpected case of horizontal gene transfer has recently been demonstrated in the laboratory between Escherichia coli and the budding yeast Saccharomyces cerevisiae ${ }^{2}$. The biological relevance of this strange union is still unclear, but the mechanism of transfer clearly resembles that of bacterial conjugation. Intrigued by the idea of "generic trans-kingdom sex", as discussed in News and Views ${ }^{3}$, we investigated whether the fission yeast Schizosaccharomyces pombe can also act as the recipient in bacterial conjugation.

Our assay for DNA transfer was based on the two-plasmid conjugation system reported previously ${ }^{2}$. Briefly, one large bacterial plasmid serves as a 'helper' to mobilize in trans a second plasmid containing the ColE1 origin of transfer (ori$T)$. Evidence for transfer of the E. coli- 